\title{
Numerical methods application to study processes in the CFB boilers combustion chambers
}

\author{
Oleg M. Koksharev ${ }^{1,}$, and Andrey V. Gil ${ }^{1}$ \\ ${ }^{1}$ National Research Tomsk Polytechnic University, 634050 Tomsk, Russia
}

\begin{abstract}
This paper presents the application of numerical calculation of a hybrid Euler-Lagrange approach to model the gas-solid flow combined with a combustion process in the CFB boiler that has been resolved by applying the ANSYS FLUENT 14.0. In this work, the numerical modelling of furnace processes at various speeds of airflow supply from below was estimated. For the design speed adopted values of $0.5,1.5,2.5$ and $5 \mathrm{~m} / \mathrm{s}$. The research object is the combustion chamber of boiler unit with CFB, with steam capacity of $230 \mathrm{t} / \mathrm{h}$.
\end{abstract}

\section{Introduction}

The constantly developing fluidized combustion technology has become competitive with a conventional pulverized coal (PC) combustion. Circulating fluidized bed (CFB) boilers can be a good alternative to PC boilers due to their robustness and lower sensitivity to the fuel quality. However, appropriate engineering tools that can be used to model and optimize the construction and operating parameters of a CFB boiler still require development. To achieve these objectives, considering the level of development of modern computer technology, it is prospective to use the methods of numerical analysis and simulation with a number of well-known advantages over experimental methods [1].

\section{Problem statement}

Currently, there is a lack of information about experimental results, and knowledge of various technological aspects of the use of fluidized bed for the implementation of any heat and mass transfer processes. To cover the needs of the different furnaces creation with a fluidized bed, a substantial progress is necessary in the field of mathematical and numerical methods modelling of various physical and chemical processes in fluidized bed. However, the process of modelling is complicated by a number of problems $[2,3]$, such as the requirement of the boundary conditions correctness, which is often almost impossible to explore theoretically. The validity of the model is most often confirmed by the practice of numerical modelling.

\footnotetext{
* Corresponding author: omk2@tpu.ru
} 
The research object is the combustion chamber of boiler unit with CFB, with steam capacity of $230 \mathrm{t} / \mathrm{h}[4,5]$ (Fig.1). The height of the furnace reaches $28 \mathrm{~m}$. The boiler has 4 burners on the front for the supply of coal fuel in the furnace and 6 burners embrasure on the back side that intended to return the inert particles and unburned organic part of the fuel. Leaving the furnace particles are separated into two streams and fed into the cyclone for separation.

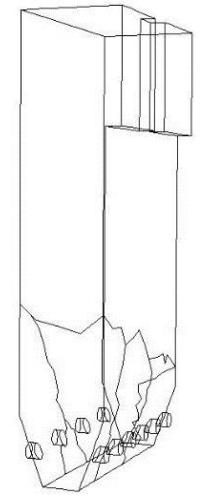

(a)

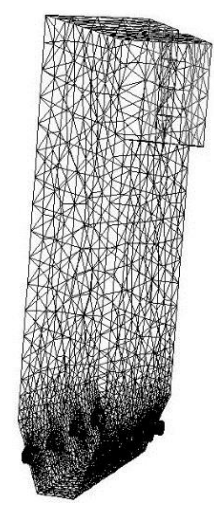

(b)

Fig. 1. The research object: (a) - 3-D model; (b) - mesh.

\section{Mathematical Model}

In this study, the Euler-Lagrange aerothermochemical technique of describing processes was used. Turbulent gas properties are calculated using the $\langle\mathrm{k}-\varepsilon »$ two-parameter turbulence model. Radiative heat transfer is represented within the P1 method approximation of spherical harmonics $[6,7]$.

Tasks are solved numerically on non-staggered grids in the Cartesian coordinate system using the relaxation method. Discretization of initial differential equations is performed by using the finite volume method. Diffusion flow on the facets of the control volume are approximated by a central difference scheme, which has the second order of accuracy. To determine the convective flows Van Leer monotonic upwind scheme of the second-order was used $[8,9]$.

\section{Results and discussion}

Figure 2 shows the concentration of substances in the furnace volume, (concentration in fractions) at a $0.5 \mathrm{~m} / \mathrm{s}$ of airflow supply from below.

In the lower part of the furnace there is a layer of $4 \mathrm{~m}$ (Fig. 2, a), where the concentration of fuel reaches the maximum value. By supplying air from below the particles are distributed throughout the volume of the furnace chamber. The concentration of fuel particles near the walls and in the central part of the furnace is uniform.

At $1.5 \mathrm{~m} / \mathrm{s}$, the height of the layer at the bottom of the furnace is lower than at a speed of $0.5 \mathrm{~m} / \mathrm{s}$, and is about $2 \mathrm{~m}$. At $2.5 \mathrm{~m} / \mathrm{s}$ of airflow supply, the height of the layer at the bottom of the furnace is lower than at a speed of $1.5 \mathrm{~m} / \mathrm{s}$, and is about $1.7 \mathrm{~m}$ (Fig. 3).

Analyzing simulation results at $5 \mathrm{~m} / \mathrm{s}$ of airflow supply from below, it can be noted that the height of dense layer of solid particles is about $0.4 \mathrm{~m}$ (Fig. 4). In addition, it has the highest distribution density of particles in the upper part of the furnace in contrast to the results at a low speed $(0.5 \mathrm{~m} / \mathrm{s})$. 


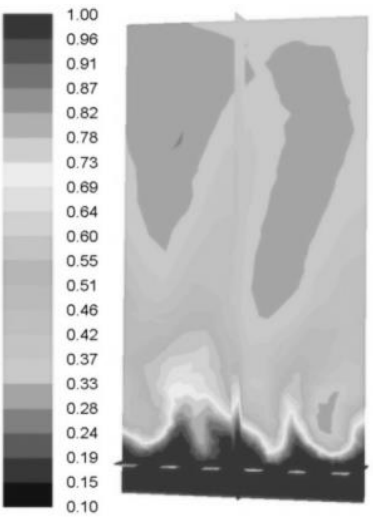

(a)

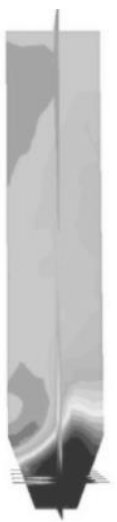

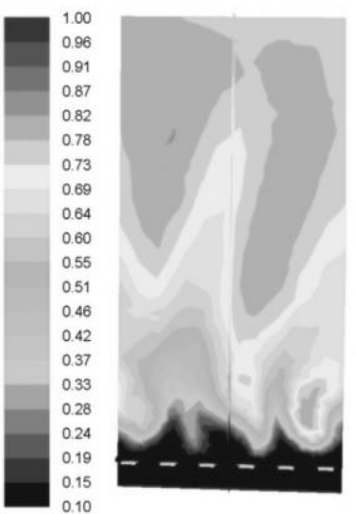

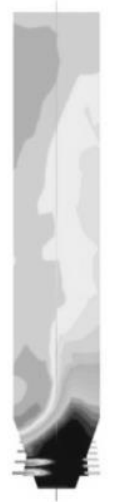

(b)

Fig. 2. Height variation of the furnace estimated phases concentration values in vertical cross-section at $0.5 \mathrm{~m} / \mathrm{s}$ of airflow supply from below: (a) particles; (b) air.

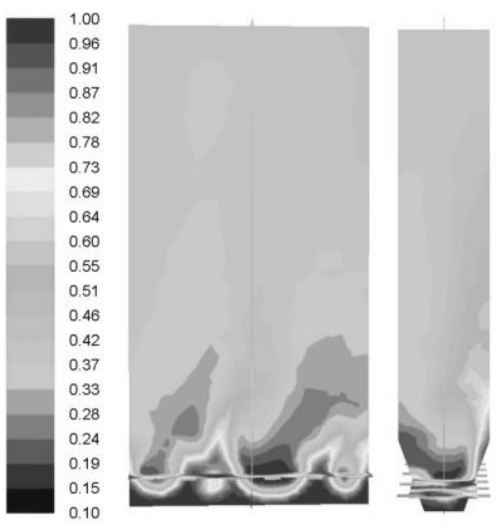

(a)

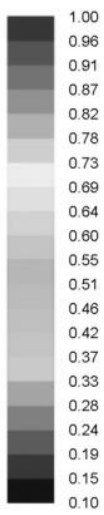

0.10

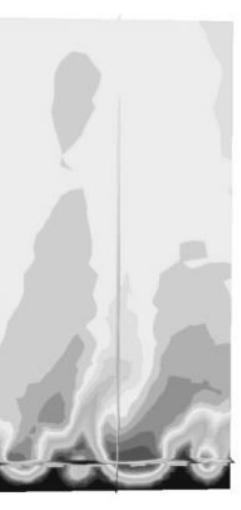

(b)

Fig. 3. Height variation of the furnace estimated phases concentration values in vertical cross-section at $2.5 \mathrm{~m} / \mathrm{s}$ of airflow supply from below: (a) particles; (b) air.
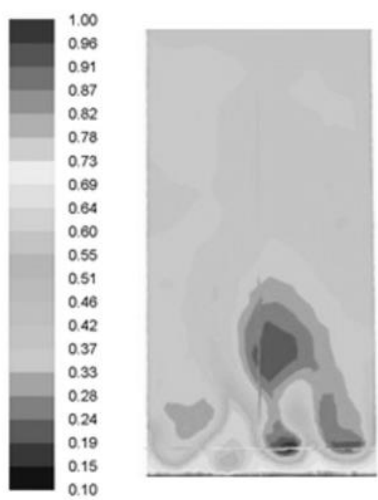

(a)

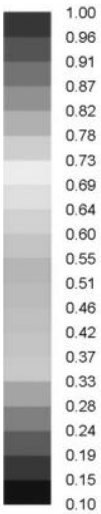

0.10
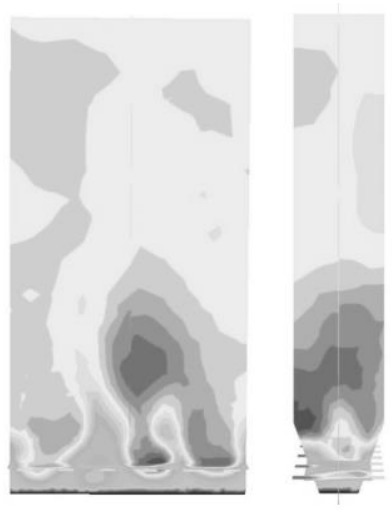

(b)

Fig. 4. Height variation of the furnace estimated phases concentration values in vertical cross-section at $5 \mathrm{~m} / \mathrm{s}$ of airflow supply from below: (a) particles; (b) air 
Figure 5 shows the change in the concentration (in fractions) of fuel in the furnace chamber height at different rates of airflow supply from below. According to the obtained results by increasing the feed rate of airflow supply the fractions volume at the exit of the furnace will increase, and in the lower part of the combustion chamber will decrease.

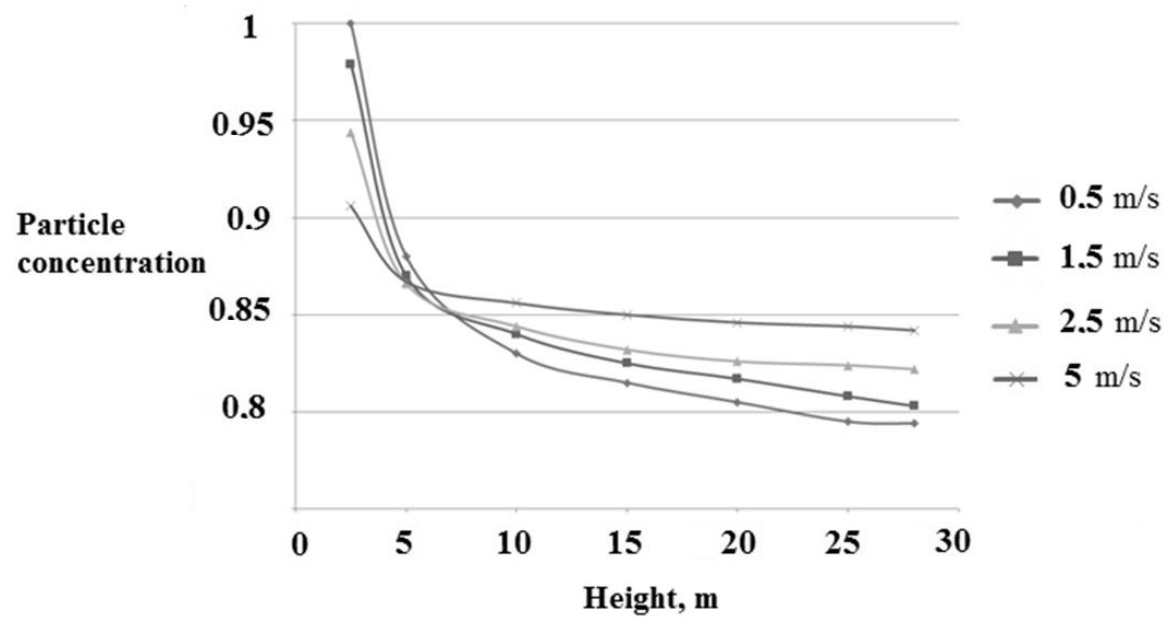

Fig. 5. Height variation of the fuel particle concentration.

\section{Conclusions}

In conclusion, in accordance with the task it can be stated that the most efficient pattern is observed at the height of the layer that is not exceed the level of the burners, not more than $2.1 \mathrm{~m}$. Consequently, the rate of airflow supply for the investigated furnace should be not less than $2 \mathrm{~m} / \mathrm{s}$.

\section{References}

1. A. Tourunen, J. Saastamoinen, H. Nevalainen, Fuel 88, 1333 (2009)

2. P. Basu, Combustion and gasification in fluidized beds (CRC Press, Boca Raton, 2006)

3. A.V. Gil, A.Y. Gil, EPJ Web Conf. 82, 01044 (2015)

4. A.V. Gil, D.A. Baturin, MATEC Web Conf. 72, 01009 (2016)

5. A.V. Gil, D.A. Baturin, IOP Conf. Ser. Mater. Sci. Eng. 93, 012003 (2015)

6. J. Xie, W. Zhong, B. Jin, Y. Shao, Y. Huang, Adv. Powder Technol. 24, 382 (2013)

7. A.V. Zavorin, A.V. Gil, P.S. Khaustov, R.B. Tabakaev, D.A. Buslov, , IOP Conf. Ser. Mater. Sci. Eng. 66, 012038 (2014)

8. M.H. Bordbar, K. Myohanen, T. Hyppanen, Appl. Therm. Eng. 76, 344 (2015)

9. A.S. Zavorin, A.V. Starchenko, S.V. Obukhov, Power Techn. Eng. 45, 42 (2011) 